\title{
ANÁLISE MULTITEMPORAL DO SUL DO MUNÍCIPIO DE SÃO GABRIEL DO OESTE, MATO GROSSO DO SUL, REGIÃO DAS NASCENTES DO RIO AQUIDAUANA, FRENTE AS ATIVIDADES ANTRÓPICAS E SUAS CONSEQUÊNCIAS
}

\author{
MULTITEMPORAL ANALYSIS OF THE SOUTH OF THE MUNICIPALITY OF SÃO \\ GABRIEL DO OESTE, MATO GROSSO DO SUL, REGION OF THE SPRINGS OF THE \\ AQUIDAUANA RIVERFRONT ANTHROPIC ACTIVITIES AND THEIR CONSEQUENCES
}

\author{
Ademir Kleber Morbeck de Oliveira \\ Doutor em Ecologia e Recursos Naturais, Universidade Anhanguera-Uniderp, Brasil \\ akmorbeckoliveira@gmail.com \\ Jorge de Souza Pinto \\ Doutor em Meio Ambiente e Desenvolvimento Regional, UFMS, Brasil \\ jorge.pinto@ufms.br \\ Rosemary Matias \\ Doutora em Química, Universidade Anhanguera-Uniderp, Brasil \\ rosematiasc@gmail.com

\begin{abstract}
Valtecir Fernandes
Doutor em Meio Ambiente e Desenvolvimento Regional, Universidade Anhanguera-Uniderp, Brasil biovfernandes@yahoo.com.br
\end{abstract}

\section{Resumo}

No estado de Mato Grosso do Sul, mais precisamente à Serra de Maracaju, apesar de sua extensão territorial, ainda é pouco conhecida em termos de seu uso e cobertura da terra, principalmente em áreas de nascentes de importantes rios que desaguam no Pantanal, sobretudo do Rio Aquidauana. Este artigo avaliou as mudanças ocorridas na paisagem na região das nascentes do Rio Aquidauana, por meio da análise do uso e ocupação da terra em um recorte temporal de trinta anos. Foram utilizadas imagens dos satélites Landsat 5 TM (1990 e 2005) e Sentinel $2^{a}$ MSI (2020), para o mapeamento da evolução do uso e ocupação da terra e obtenção do índice de vegetação - NDVI (Normalized Difference Vegetation Index). Os resultados apontaram uma gradativa perda de áreas florestais (32,93\% em 1990; $27,79 \%$ em 2020) e aumento das áreas de lavouras (19,15\% em 1990; $29,79 \%$ em 2020). Apesar da perda de áreas florestais, os índices de NDVI permaneceram estáveis em toda a região, com maiores valores nas áreas mais acidentadas, indicando que os remanescentes apresentam qualidade ambiental.

Palavras-chave: Uso e ocupação do solo, Índice de Vegetação por Diferença Normalizada, Serra de Maracaju. 


\section{Abstract}

In the State of Mato Grosso do Sul, more precisely the Serra de Maracaju, despite its territorial extension, it is still little known regarding its use and land cover, mainly in areas of springs of important rivers that flow into the Pantanal, especially the Aquidauana River. This article aimed to evaluate the changes in the landscape along the headwaters of the Aquidauana River through the analysis of land use and land cover over a thirty-year time frame. Images from the Landsat 5 TM (1990 and 2005) and Sentinel $2^{a}$ MSI (2020) satellites were used to map the evolution of land use and occupation and obtain the NDVI (Normalized Difference Vegetation Index). The results showed a gradual loss of forest areas $(32.93 \%$, in 1990 , to $27.79 \%$, in 2020 ) and an increase in the areas of crops $(19.15 \%$, in 1990 , to $29.79 \%$, in 2020). Despite the loss of forest areas, the NDVI indexes remained stable across the region, with higher values in the more rugged areas of the mountain range, indicating that the remnants have environmental quality

Keywords: Land use and occupation, Normalized Difference Vegetation Index, Serra de Maracaju.

\section{INTRODUÇÃO}

No estado de Mato Grosso do Sul, o monitoramento da superfície terrestre vem utilizando produtos de sensores orbitais com muita eficácia no processo de identificação de cobertura vegetal, tal como relatado por Rego e Valeri (2008), Oliveira et al. (2017ab) e Lima et al. (2020) na Serra de Maracaju ou Oliveira et al. (2009), na Serra da Bodoquena. As técnicas de interpretação e classificação digital em imagens de satélite são utilizadas no mapeamento do ambiente, visando auxiliar na implantação de medidas preventivas ou corretivas no uso da terra. O uso dos sensores multiespectrais e a análise do uso e ocupação do solo e/ou o uso e cobertura da terra tornaram-se aspectos de interesse primordial para a compreensão dos padrões de organização do espaço físico, cada vez mais alterado, facilitando seu diagnóstico de ocupação (LIU, 2015).

Tal ocupação pode trazer importantes interferências na dinâmica natural em uma bacia hidrográfica e essa situação resulta em impactos negativos, podendo levar a processos erosivos e assoreamento dos recursos hídricos, entre outras implicações (BARBOSA; NOVO; MARTINS, 2019). Neste contexto, a análise multitemporal, que consiste na extração de informações provenientes de dados de um mesmo local obtidos em momentos distintos, permite detectar as mudanças pelas variações identificadas nas séries analisadas (PARANHOS FILHO; GAMARRA, 2021).

Por este motivo, o monitoramento do uso e da cobertura da terra é uma tarefa essencial no conhecimento da realidade ambiental, podendo contribuir na busca de soluções de problemas existentes. O termo "mudança de uso e cobertura da terra" tem o 
significado de transformações quantitativas na paisagem (acréscimo ou decréscimo de uma determinada classe de uso e cobertura da terra), possível de ser observado com base na análise multitemporal de cenas de imagens de satélite obtidas nos mesmos locais, em diferentes períodos, permitindo a avaliação das mudanças ambientais (BRIASSOULIS, 2019).

Juntamente ao uso e ocupação da terra, uma das formas de entender as mudanças ambientais é a avaliação da vegetação e sua fitomassa, por meio da utilização do Índice de Vegetação por Diferença Normalizada (NDVI), que pode ser definido como a combinação de dados de bandas espectrais, selecionadas com o objetivo de realçar a relação dos dados com os parâmetros da vegetação e degradação (PETTORELLI, 2014).

Desta maneira, são técnicas ligadas ao sensoriamento remoto que surgem como instrumento de elevado potencial, tanto na coleta como no processamento das informações referentes às áreas agrícolas (FORMAGGIO; SANCHES, 2017) ou de preservação, em regiões de relevante interesse ecossistêmico (PONZONI; SHIMABUKURO; KUPLICH, 2012). Os dados gerados por sensores orbitais têm utilidade em várias aplicações ambientais, que incluem a avaliação do nível de preservação ou desmatamento de ecossistemas, por exemplo (GUEDES; SILVA, 2018). Desta maneira, satélites equipados com sensores multiespectrais têm importante papel na obtenção de imagens do ambiente terrestre. Entre estes se destaca a série Landsat (1-8), lançados entre 1972 e 2013, devido à boa qualidade de suas imagens e disponibilização gratuita pelo United States Geological Survey. Recentemente foi apresentada a missão Sentinel-2 (Sentinel-2 ${ }^{\mathrm{a}}$ - 2015 e, Sentinel$2^{\text {b }}$ - 2017), para dar continuidade a missão Ladsat, sendo que os novos satélites possuem mais recursos, como um sensor multiespectral MSI com 13 bandas espectrais (entre $443 \mathrm{e}$ $2190 \mathrm{~nm}$ ) e resolução espacial de $10 \mathrm{~m}$ para as bandas do visível e por isso, melhor resolução espacial das imagens (MIRANDA et al., 2019).

As técnicas de sensoriamento remoto são importantes para o Brasil, pois as diferentes regiões brasileiras sofrem de problemas ecossistêmicos similares, todos relacionados às atividades antrópicas, muitas vezes executadas de maneira incorreta. $\mathrm{O}$ estado de Mato Grosso do Sul está inserido nessa situação, destacando-se o avanço contínuo das monoculturas, tanto a silvicultura (região leste), cana-de-açúcar e soja (centrosul) e soja (centro e norte), sendo à Serra de Maracaju um exemplo de área com forte pressão ambiental. De acordo com Bononi et al. (2017) e Lima et al. (2020), ela divide o estado em duas partes, a oeste a Bacia do Alto Paraguai, dividida em uma região alta (Planalto), onde nascem os rios que formam a bacia hidrográfica e uma região baixa e plana 
(Pantanal), periodicamente inundada pelo Rio Paraguai e afluentes. A leste, a Bacia do Paraná, com morros de altitudes médias de $900 \mathrm{~m}$, próximos ao município de Aquidauana, em direção a São Gabriel do Oeste.

O município de São Gabriel do Oeste, um relevante produtor de commodities agrícolas, como a soja, registra forte crescimento das atividades relacionadas ao agronegócio, nas últimas décadas (OLIVEIRA et al., 2017b). Uma característica marcante da região é possuir inúmeras nascentes que formam importantes rios do Pantanal, uma extensa planície de inundação localizada no extremo oeste do estado (JOIA; ANUNCIAÇÃO; PAIXÃO, 2018). Entre estes rios pode-se destacar o Aquidauana, importante afluente da margem direita do Rio Miranda, formando o chamado Pantanal de Miranda-Aquidauana, uma importante área de diversidade biológica (OLIVEIRA et al., 2011). Neste sentido, Lima et al. (2020) destacam a importância hídrica da Serra de Maracaju devido à grande concentração de mananciais e nascentes, que formam importantes rios no estado de Mato Grosso do Sul, com a conservação/preservação de suas áreas florestais sendo importantes para a manutenção de seus recursos hídricos, além de permitir a recarga de aquíferos subterrâneos importantes, como o Aquífero Guarani. Entretanto, os autores mencionam que a aptidão agrícola da região exerce forte pressão sobre as paisagens nativas, levando a sua descaracterização e perda de qualidade.

Logo, frente à importância ambiental, econômica e os poucos estudos realizados nas nascentes do Rio Aquidauana na Serra de Maracaju, componente de uma bacia que tem importante papel nas dinâmicas hidrosedimentares do Pantanal, objetivou-se: avaliar se a mudança de uso e cobertura da terra nesta parte da bacia hidrográfica, ao longo do período de 1990 a 2020, tem significado uma ameaça a dinâmica hidrológica, tendo como instrumento complementar de quantificação e análise o índice de vegetação por diferença normalizada.

\section{MATERIAL E MÉTODOS}

\subsection{Contexto geoecológico da área de estudo}

A área estudada possui $434,69 \mathrm{~km}^{2}$, localizada no município de São Gabriel do Oeste, região de nascentes do Rio Aquidauana, entre as coordenadas $54^{\circ} 47^{\prime} 41^{\prime \prime} \mathrm{O}, 19^{\circ} 35^{\prime}$

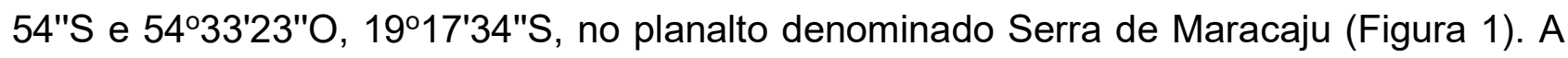
delimitação da área foi adquirida junto ao Sistema Interativo de Suporte ao Licenciamento Ambiental do Instituto de Meio Ambiente do Mato Groso do Sul (SISLA/IMASUL). 


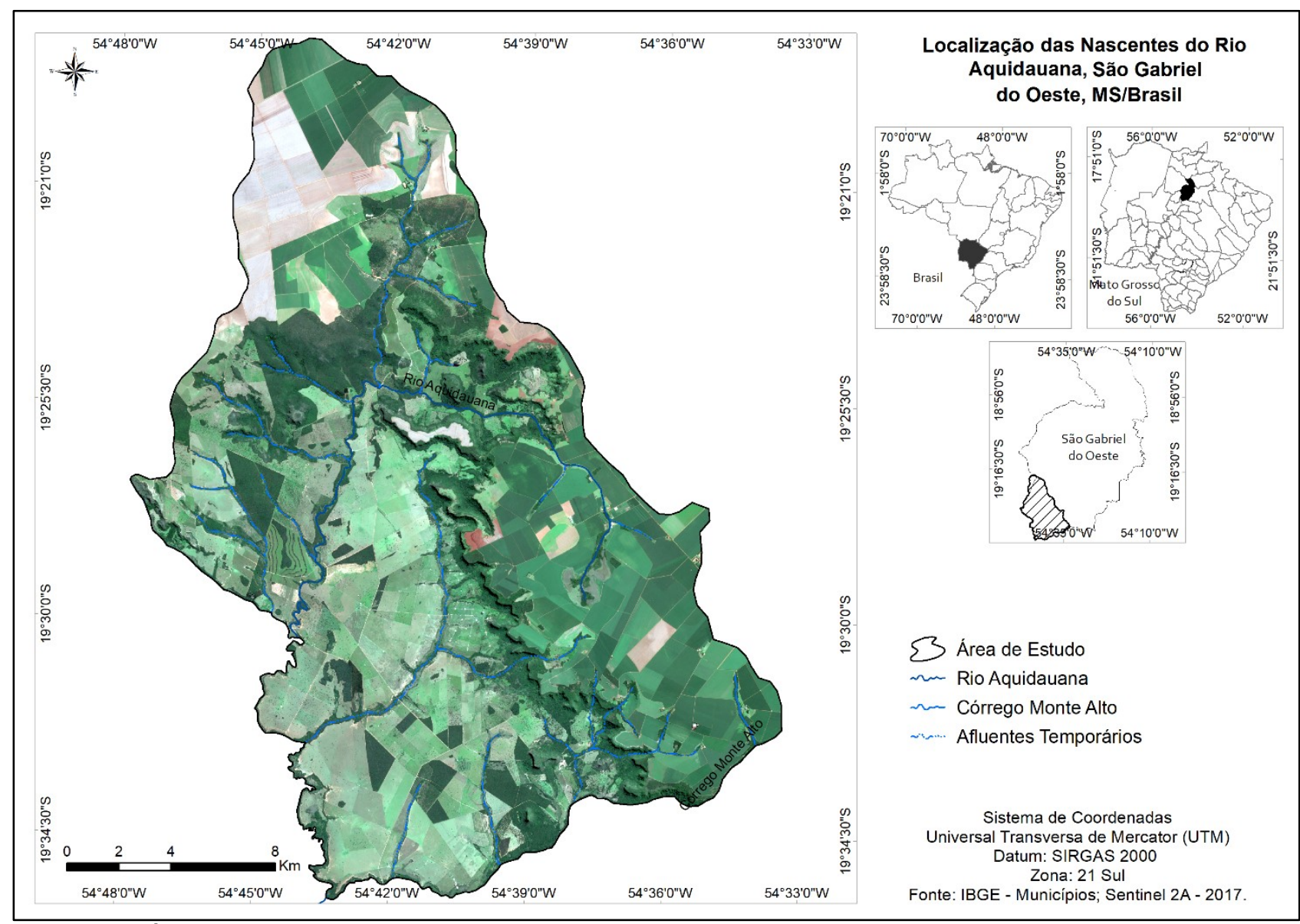

Figura 1 - Área de estudo, localizada no município de São Gabriel do Oeste, Mato Grosso do Sul, Brasil, 2020. Fonte: os autores.

Em relação ao clima, a área de estudo está localizada sobre a faixa zonal (folha Aquidauana) entre os climas controlados pelas massas equatoriais e tropicais e os climas controlados pelas massas tropicais e polares, com índices pluviométricos variando entre $1.200 \mathrm{~mm}$ (norte) a $1.500 \mathrm{~mm}$ (sul), com uma estação seca e outra chuvosa (ZAVATTINI, 2009).

Segundo Assis et al. (2003) e Lima et al. (2020), a geomorfologia da região, localizada entre os compartimentos do Patamar do Rio Aquidauana (nascentes) e das Furnas do Sudoeste do Chapadão é bastante diversificada. As feições encontradas são: Colinas (elevações de baixa altitude de formas arredondadas e pequenos declives); Escarpas (elevação súbita do solo, superior a $45^{\circ}$ e de formas íngremes); Furnas (cavidades originadas muitas vezes por erosões provocadas por água ou vento); e, Patamar do Alto Rio Aquidauana com cotas entre 360 a 680 m. Este patamar compreende as superfícies de Interflúvios do Ribeirão Fala Verdade e Rio Aquidauana e Superfícies de Interflúvios em Rampa do Baixo Barreirinho e Morro Alto, apresentando dissecados 
tabulares em rampas e colinas e declividades onduladas, com escoamento superficial favorecendo a instalação de ravinas.

A hidrografia da região é composta por duas sub-bacias, sendo os principais cursos d'água o Rio Coxim e Rio Aquidauana, nos quais desaguam os córregos Cachoeirinha, Barreirinha, Mata Comprida, Morro Alto, Bonito e Pulador, com os recursos hídricos tendo os usos de captação para abastecimento público e recepção de efluentes industriais e domésticos, além da pesca e balneabilidade (ASSIS et al., 2003).

A região é composta por fitofisionomias do bioma Cerrado, entre as quais observase a presença de Savana Arbórea Densa e Encrave Savana, Floresta Estacional e Veredas, além de Áreas Agrícolas e Pastagens (MATO GROSSO DO SUL, 2015; LIMA et al., 2020).

Entre as principais classe de solos encontrados na região se destacam: (1) Latossolo Vermelho Distrófico Típico, com horizonte B pouco profundo, textura argilosa a médio argilosa, bem a fortemente drenado, distrófico e com baixa capacidade de troca catiônica (CTC); (2) Latossolo Vermelho-Amarelo, argiloso, profundo, moderadamente drenado, baixa CTC e alta saturação por alumínio, com tendência a erodibilidade, quando sem vegetação; (3) Neossolo Quartzarênico, pouco desenvolvido, profundo, excessivamente drenado, com grande concentração de areia, normalmente distrófico e com baixa CTC e alta susceptibilidade à erosão; (4) Gleissolo, pouco profundo ou profundo, mal drenado, com textura média e argilosa e distrófico, permanente ou periodicamente saturado por água; (5) Neossolo Litólico, normalmente pedregoso e encontrado em áreas de afloramento rochoso, pouco desenvolvido e susceptível a problemas de erosão (ASSIS et al., 2003).

A região de estudo situa-se no domínio da Bacia Sedimentar do Paraná, com uma sequência de rochas sedimentares e vulcânicas de origem continental. Entretanto, as intervenções antrópicas nas paisagens levaram a mudanças no ritmo e/ou na forma de seu desenvolvimento, resultando em uma constante evolução de determinadas fisionômicas (ASSIS et al., 2003).

\subsection{Processamento Digital de Imagens de Satélite}

Na elaboração do estudo sobre uso e cobertura da terra foram utilizadas imagens do satélite Landsat 5/TM, bandas 3 (vermelho), 4 (infravermelho próximo) e 5 (infravermelho médio) dos anos de 1990 e 2005, adquiridas gratuitamente no site do Instituto Nacional de Pesquisas Espaciais (INPE), pelo Catálogo de Imagens <http://www.dgi.inpe.br/CDSR/>. Em 2020 foram empregadas imagens do satélite Sentinel $2^{a}$, com as bandas 2 (azul), 3 
(verde) e 4 (vermelho), disponibilizadas por meio do site da United States Geological Survey (USGS), disponível em https://earthexplorer.usgs.gov/ (Tabela 1). As datas das imagens escolhidas estão relacionadas a sua qualidade, com pouca ou nenhuma cobertura de nuvens, o que permitiu a melhor interpretação das áreas avaliadas.

Tabela 1 - Satélites utilizados com seus respectivos sensores, órbitas, ponto, resolução espacial e data das imagens

\begin{tabular}{cccccc} 
Satélites & Sensor & Órbita & Ponto & Resolução Espacial & Data \\
\hline Landsat 5 & TM & 225 & 74 & 30 metros & $05 / 04 / 1990$ \\
Sentinel 2 & MSI & 135 & 111 & 10 metros & $09 / 03 / 2005$ \\
\hline
\end{tabular}

Fonte: os autores.

As imagens utilizadas nas bandas do visível foram escolhidas por serem muito usuais e aplicáveis para mapeamentos do uso e ocupação da terra. Também é importante salientar que foram empregadas duas famílias de imagens de satélite (Landsat e Sentinel) que, apesar que exibirem resoluções espaciais distintas, atendem à escala pretendida na análise e objetivos traçados. Sob tal perspectiva, Martinelli (1994) afirma que a escala se vincula à Área Mínima Mapeável (alcance do erro aceitável em cartografia), obedecendo à cartografia a ser produzida. Desta maneira, na escala de 1:25.000, aplica-se uma Área Mínima Mapeável compatível com as resoluções das imagens de satélite utilizadas, sem prejuízo ao dado espacial.

Foi feita uma escolha prévia pelos anos analisados, primeiramente utilizando o primeiro ano das imagens Landsat 5 (1990). Posteriormente, procurou-se um hiato de quinze anos entre os dois próximos anos de análise; neste sentido, o ano de 2005 possibilitou trabalhar as imagens obtidas. Já para o ano mais recente, buscou-se uma atualização para datas mais próximas a finalização do trabalho e das atividades de campo (verificação da verdade terrestre), possibilitando dados atuais que possam ser trabalhados e analisados. Todas as imagens foram importadas e, para as imagens Landsat 5, foi necessário seu georreferenciamento por meio de pontos de controle passíveis de identificação, utilizando as imagens Sentinel $2^{\text {a }}$. Estas, por já se apresentarem georreferenciadas, podem ser utilizadas como referência no processo e trabalhadas no SIG Spring 5.2.6 e SIG ArcGis 10.

Após o georreferenciamento, o contraste foi executado no SIG Spring 5.2.6 de modo a melhorar sua qualidade, utilizando a opção equalizar histograma. A partir deste ponto, foi realizada a interpretação da cobertura vegetal e uso da terra por meio de classificação não supervisionada por regiões, utilizando-se o classificador não-supervisionado Histograma, 
um clustering de regiões em que se busca, por meio de suas assinaturas espectrais, definir os grupos de assinaturas semelhantes e separá-las em classes. Para tanto, foram utilizados os valores de pixels (20) e similaridade (20), sendo o resultado satisfatório dentro do objetivo da pesquisa. Desta maneira, foram definidos cinquenta temas distintos de assinaturas e após tal procedimento, foi realizada a validação utilizando a imagem de satélite mencionada, verificando e correlacionando cada segmento às classes de cobertura vegetal e uso da terra (ZANOTTA; FERREIRA; ZORTEA, 2019).

A classificação das imagens permitiu sua divisão em sete classes temáticas da cobertura vegetal e uso da terra, com nomenclatura baseada no Manual Técnico da Vegetação do IBGE (2012) (Quadro 1).

Quadro 1 - Chave de interpretação das classes temáticas de cobertura vegetal e uso da terra na área das nascentes do Rio Aquidauana, São Gabriel do Oeste, Mato Grosso do Sul, entre 1990 e 2020

\begin{tabular}{|c|c|}
\hline $\begin{array}{l}\text { Tipo de cobertura } \\
\text { vegetal e uso da terra }\end{array}$ & Descrição \\
\hline Pastagens & Área de plantio predominante de braquiárias (Brachiaria spp. e Urochloa spp.) \\
\hline Áreas florestais & $\begin{array}{c}\text { Locais com a presença de vegetação de porte arbóreo nativa da região, como } \\
\text { o Cerrado (encrave cerrado e cerradão), Floresta Estacional Semidecidual e } \\
\text { Decidual e, Formações Ripárias (mata ciliar e de galeria) }\end{array}$ \\
\hline Culturas & Área de plantio de grãos, como soja (Glycine max L.) e milho (Zea mays L.) \\
\hline Áreas úmidas & $\begin{array}{l}\text { Veredas - áreas úmidas com a presença da palmeira conhecida com buriti } \\
\text { (Mauritia flexuosa L.f.) }\end{array}$ \\
\hline Água & Regiões com a presença de rios, córregos, lagoas e açudes \\
\hline Áreas edificadas & $\begin{array}{l}\text { Locais onde se encontram sedes de propriedades rurais, silos e outras } \\
\text { estruturas físicas }\end{array}$ \\
\hline Solo exposto & Áreas de cultivo sem fitomassa \\
\hline
\end{tabular}

Fonte: baseada no Manual Técnico da Vegetação do IBGE (2012).

Após essa classificação, foi feita a verificação, etapa essencial no mapeamento da cobertura vegetal e uso da terra, por meio de saída de campo, confirmando os dados classificados com a realidade terrestre (verdade real), utilizando-se um GPS Garmin - Vista para validar a exatidão dos padrões mapeados.

\section{3 Índice de Vegetação por Diferença Normalizada (NDVI)}

Em relação ao índice de NDVI dos anos analisados, que busca qualificar as áreas conforme a quantidade de vegetação existente, utilizou-se as mesmas imagens, por meio do uso de bandas diferentes. Para as imagens Landsat 5, foram utilizadas as bandas 3 (vermelho) e 4 (infravermelho próximo) e, Sentinel $2^{\mathrm{a}}$, bandas 4 (vermelho) e 8 (infravermelho próximo).

O cálculo do NDVI foi feito a partir da diferença entre as reflectâncias das bandas do infravermelho próximo e vermelho dividido pela soma das reflectâncias das duas 
bandas. Foi utilizado o ArcGis 10, por meio da ferramenta Spatial Analyst Tools > Map Algebra > Raster Calculator, com o cálculo do NDVI seguindo a equação: NDVI = IVP - V / IVP + V, em que IVP é valor da reflectância da banda no infravermelho próximo e $V$ é o valor de reflectância da banda no vermelho.

Os índices de NDVI variam de -1 a 1 e os valores que se aproximam de um indicam áreas de vegetação arbórea densa e/ou arbórea em crescimento, valores próximos a zero, áreas de solo exposto e, valores negativos, áreas sem vegetação em diversas intensidades.

\section{RESULTADOS E DISCUSSÃO}

Os dados obtidos indicam que o processo de substituição das matas nativas é progressivo na região, com perda de vegetação em todas as décadas avaliadas (Tabela 2 e Figura 2), uma situação que vem ocorrendo em diversas áreas de Mato Grosso do Sul, mesmo em locais mais íngremes. Esta dinâmica é relacionada ao avanço das atividades agropecuárias, como relatado por Oliveira et al. (2009), ao avaliar a vegetação da Serra da Bodoquena, uma região montanhosa situada na borda sudoeste do Pantanal, demonstrando que a perda de áreas florestais é relevante e traz inúmeras consequências negativas ao equilíbrio deste ambiente, fragilizado frente à ação antrópica. Lima et al. (2020), avaliando as paisagens da Serra de Maracaju (folhas Aquidauana, Ribeirão do Taquaruçu e Nioaque), também constataram que as dinâmicas territoriais historicamente construídas para a produção de commodities para a exportação são as responsáveis pelas transformações das paisagens, por meio do desmatamento e avanço da agropecuária.

Tabela 2 - Análise multitemporal do uso e ocupação da terra na área das nascentes do Rio Aquidauana, São Gabriel do Oeste, Mato Grosso do Sul, em 1990, 2005 e 2020

\begin{tabular}{|c|c|c|c|c|c|c|}
\hline \multirow{3}{*}{ Classes } & \multicolumn{2}{|c|}{1990} & \multicolumn{2}{|c|}{2005} & \multicolumn{2}{|c|}{2020} \\
\hline & \multicolumn{2}{|c|}{ Área } & \multicolumn{2}{|c|}{ Área } & \multicolumn{2}{|c|}{ Área } \\
\hline & $\mathbf{k m}^{2}$ & $\%$ & $\mathrm{~km}^{2}$ & $\%$ & $\mathrm{~km}^{2}$ & $\%$ \\
\hline Culturas & 83,24 & 19,15 & 112,82 & 25,95 & 129,51 & 29,79 \\
\hline Áreas Florestais & 143,14 & 32,93 & 134,21 & 30,87 & 120,81 & 27,79 \\
\hline Pastagem & 145,78 & 33,54 & 151,00 & 34,74 & 146,48 & 33,70 \\
\hline Solo Exposto & 60,24 & 13,86 & 33,67 & 7,75 & 36,37 & 8,37 \\
\hline Áreas Urbanizadas & 0,06 & 0,01 & 0,90 & 0,21 & 1,20 & 0,28 \\
\hline Áreas Úmidas & 1,22 & 0,28 & 1,19 & 0,27 & 1,02 & 0,23 \\
\hline Água & 1,00 & 0,23 & 0,90 & 0,21 & 0,80 & 0,18 \\
\hline Total & 434,69 & 100,00 & 434,69 & 100,00 & 436,19 & 100,34 \\
\hline
\end{tabular}

Fonte: os autores. 


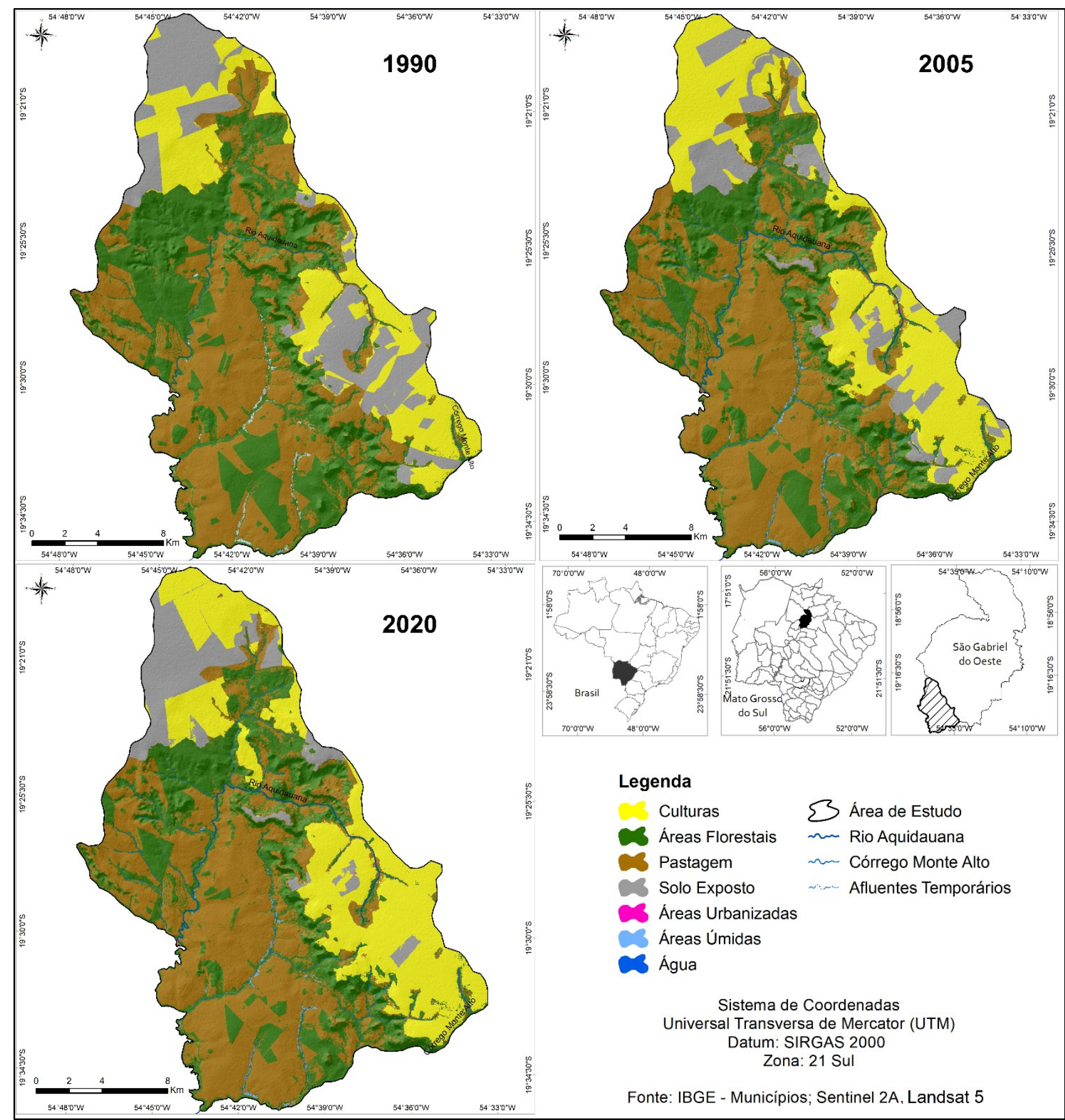

Figura 2 - Uso e cobertura da terra na região das nascentes da bacia hidrográfica do Rio Aquidauana, município de São Gabriel do Oeste, Mato Grosso do Sul, em 1990, 2005 e 2020 (Sistemas de coordenadas Universal Transversa de Mercator - Datum: SIRGAS 2000 - Zona 22 Sul). Fonte: os autores.

As áreas de culturas agrícolas apresentaram um avanço significativo entre os anos analisados, fazendo com que sua abrangência, de $83,24 \mathrm{~km}^{2}$ em 1990, passasse para $112,82 \mathrm{~km}^{2}$ em 2005 e, 129,51 km² em 2020, aumentando a área de cultivo em 10,64\% (64,3\% de crescimento) (Tabela 2), sobretudo na porção norte, centro leste e sudeste do alto curso da bacia hidrográfica. Por outro lado, as regiões cultivadas com gramíneas (pastagens) se mantiveram similares (entre 33 e 34\% da área), pois elas ocuparam novos territórios (Figura 2), por meio do desmatamento e plantio de braquiária. Dessa maneira, 
pode-se afirmar que a expansão no cultivo de grãos ocorreu em antigas pastagens e áreas florestais, explicando a redução das áreas florestadas. A expansão das áreas de cultivo é relacionada ao aumento de valor das commodities agrícolas, como a soja e o milho, levando os produtores a buscarem novas áreas de plantio (MARANHÃO; VIEIRA FILHO, 2016).

Segundo Mato Grosso do Sul (2015), em algumas áreas do município apenas a criação de gado é adequada devido a predominância de Solos Litólicos (solos rasos) e Neossolos Quartzarênicos (solos arenosos). Estes tipos de ambiente possuem baixa aptidão agrícola devido a estrutura e restrição nutricional dos solos, indicando limitações para cultivos mais exigentes do que pastagens (ASSIS et al., 2003). De acordo com Guerra e Jorge (2014), áreas com estas características necessitam de manejo adequado, pois apresentam vulnerabilidade aos processos erosivos quando perdem sua cobertura vegetal.

É interessante ressaltar que na área estudada ocorreu uma redução de 39,6\% de áreas de solos expostos, em relação a 1990, principalmente na região leste (Tabela 2 e Figura 2). Estes locais estavam relacionados ao gradeamento (solos sem cobertura vegetal) para utilização no plantio de cereais (agricultura), demonstrando melhor aproveitamento da área e intensificação de atividades econômicas, por meio de cultivo na época da coleta de imagens. O aumento das áreas urbanizadas (1990 - 0,01\%; 2020 - 0,28\%) (Tabela 2), apesar da resolução das imagens de satélites serem distintas, também pode ser um indicativo de que as atividades econômicas relacionadas ao agronegócio estão mais intensas, levando ao aumento da infraestrutura produtiva, como novos silos, por exemplo.

De acordo com Assis et al. (2003), o agronegócio na região tende a continuar se expandindo e substituindo as florestas nativas, com vários danos ao ambiente, fator relacionado principalmente ao aumento da exportação de grãos e carne para outros países da América do Norte, Ásia e Oriente Médio. Maranhão e Vieira Filho (2016) afirmam que a partir de 2000 ocorreu um crescimento do comércio mundial, motivado pelo aumento da demanda de países emergentes, o que proporcionou o boom das commodities, favorecendo a ocupação de novas áreas agrícolas. Assis et al. (2003) descrevem que a instalação de grandes empresas de beneficiamento (frigoríficos de aves, suínos e bovinos, silos para armazenamento de grãos, fábricas de ração animal e companhias de mineração de calcário, por exemplo) contribuíram para a ocupação da região.

$\mathrm{Na}$ região em estudo, as culturas agrícolas se sobressaem em terrenos suavemente ondulados (declividade entre 0 a $20 \%$, extremamente aptos a moderadamente aptos à mecanização) do planalto, que favorecem a redução dos custos de cultivo. As áreas agrícolas implantadas no planalto se desenvolveram separadamente da pecuária, devido 
ao fator qualidade do solo e mecanização. Porém, este ponto tornou-se importante apenas a partir de 1970, com a chegada de novos migrantes a região, iniciando o plantio de variedades de soja adaptadas ao Cerrado (ASSIS et al., 2003), além de processos de correção do solo.

Esta situação é demonstrada na classificação das imagens, que apontam o desenvolvimento da agricultura sendo mais intenso no planalto, região norte e leste; por outro lado, em direção a planície (oeste) ocorre o predomínio de pastagens (Figura 2). Brasil (1982) e Mato Grosso do Sul (2015) confirmam que na Serra de Maracaju, em maiores altitudes e áreas de menor declividade $(-20 \%)$, ocorrem Latossolos Vermelhos, por exemplo, propícios para o cultivo de grãos, como a soja e o milho. Por outro lado, na direção da planície pantaneira existe a maior presença de Neossolos impróprios a agricultura. Dessa maneira, áreas com menor declividade e com solos mais adequados são convertidas em áreas agrícolas, enquanto as demais, em pastagens. Lima et al. (2020) confirmam esta situação, demonstrando que as estruturas das paisagens que apresentam maiores declividades possuem os maiores índices de preservação da áreas florestais. Por outro lado, áreas de relevo com maior suavidade e aptas para as atividades agropecuárias possuem o menor nível de preservação. De acordo com Cândido, Silva e Barbosa (2015), em áreas mais propicias ocorre a predominância de grandes monoculturas altamente mecanizadas, que representam a forma mais comum de exploração, situação encontrada na região em estudo.

A vegetação florestal passou de 143,14 km² em 1990 para 120,81 km² em 2020, diminuição de 15,60\%, com a supressão principalmente das Florestas Estacionais. Apesar de sua redução, essas áreas ainda ocupam $27,79 \%$ da região, principalmente em locais de declive mais acentuado, de difícil acesso. Esta situação é confirmada por Lima et al. (2020) em estudos na região, em um padrão similar ao descrito por Oliveira et al. (2009) na serra da Bodoquena, onde apenas os pontos de difícil acesso ainda apresentam uma vegetação de porte arbóreo bem conservada.

As Floresta Estacionais (Figura 3) são descritas por Mato Grosso do Sul (2015) e Damasceno-Junior et al. (2018) como ocorrendo nas baixadas sobre solos alcalinos férteis, com baixa diversidade em termos de número de espécimes, porém, com grande importância devido ao alto número de espécies endêmicas, sendo consideradas áreas prioritárias para conservação da biodiversidade. Rego e Valeri (2008) e Damasceno-Junior et al. (2018) escrevem que estas florestas se constituem no tipo vegetacional que ocupa, proporcionalmente, a menor área no estado. A sua dispersão fitogeográfica limita-se 
principalmente a região noroeste, encontrando-se separadas uma das outras, por até dezenas de quilômetros, formando comunidades únicas, sempre ameaçadas pelo avanço das atividades antrópicas.

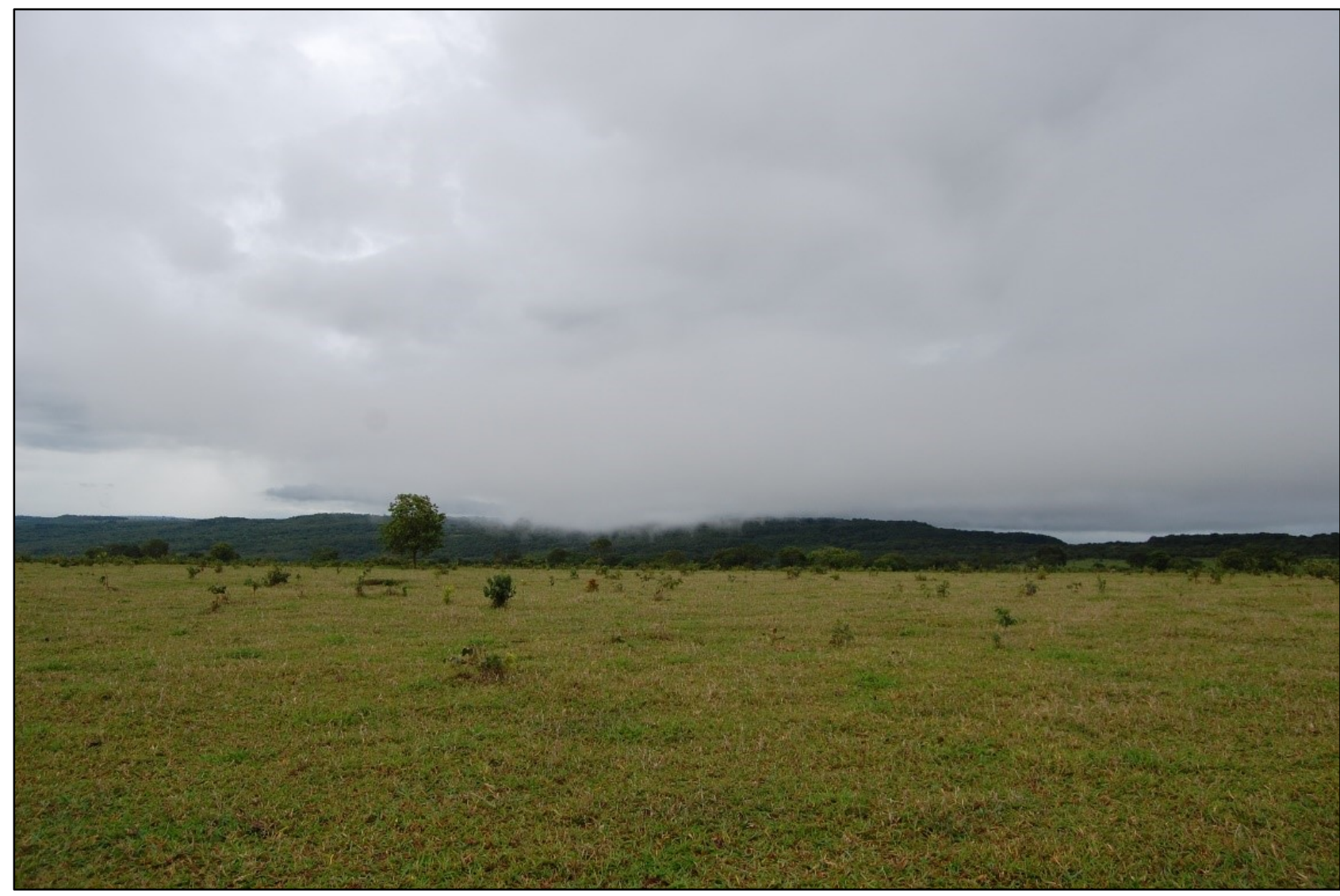

Figura 3 - Florestas estacionais e pastagens na região das nascentes da bacia hidrográfica do Rio Aquidauana, município de São Gabriel do Oeste, Mato Grosso do Sul.

Fonte: os autores.

No entanto, um aspecto ainda pouco discutido é que a região também é um local de recarga do Aquífero Bauru e Aquífero Guarani, importantes reservas de água subterrânea de países do hemisfério sul, como a Argentina, Brasil, Paraguai e Uruguai. A retirada da vegetação diminui os processos de infiltração de água das chuvas, devido ao seu escoamento mais rápido. Além disso, os agrotóxicos utilizados (inseticidas e herbicidas, entre outros), são uma fonte potencial de contaminação da biota. De acordo com Pignati et al. (2017), Mato Grosso do Sul é um dos estados da federação que mais utiliza agrotóxicos, uma situação que aumenta o risco de contaminação das águas superficiais e subterrâneas, o que também ameaça à saúde da população.

Outra consequência dos processos de desmatamento é fragmentação de hábitats, isolando espécies e tornado o ambiente mais pobre e susceptível a outros impactos antrópicos (CARVALHO; MARCO JÚNIOR; FERREIRA, 2009). Harris et al. (2006) 
descrevem que ocorre uma grande supressão da cobertura original nos Planaltos que cercam o Pantanal, com tendência de aumento nestes valores devido o valor das commodities. A correlação entre desmatamento e pecuária e agricultura intensiva também é citada por Rivero et al. (2009) em regiões da Amazônia. Os autores escrevem que essa tendência é reforçada pelo crescimento nacional e internacional da demanda de commodities e que as políticas públicas para a redução do desflorestamento deveriam ser cumpridas, reduzindo a força dos processos que produzem a sua expansão e os problemas ambientais derivados desta situação.

Além disso, os solos originados de rochas areníticas, quartzíticas e basálticas, recém intemperizadas, como os que ocorrem na Serra de Maracaju, são pobres em nutrientes e em matéria orgânica, porosos e de estrutura frágil e, susceptíveis à erosão hídrica e eólica, principalmente quando destituídos de vegetação. De tal forma, essas áreas, com grande susceptibilidade a erosão, associadas ao manejo incorreto do solo e ausência de práticas conservacionistas, permitem processos de erosão hídrica, gerando problemas, principalmente na área ocupada por pastagens degradadas (GUERRA; JORGE, 2014).

Oliveira et al. (2009) relatam que áreas de solo exposto, pastagens degradadas e diminuição das áreas florestais são preocupantes, pois quando em área com declividade de $8 \%$, por exemplo, já pode ocorrer processos erosivos, levando a perda da camada superficial do solo e a formação de voçorocas. Os autores também associam a erosão nas pastagens ao assoreamento de rios e córregos, além de diminuir os processos de recarga dos aquíferos subterrâneos. É importante ressaltar que nesta situação, mesmo pequenas restrições na recarga podem levar a quebra de perenidade de muitos cursos de água, pois a área do município de São Gabriel do Oeste integra a frágil zona de recarga do Aquífero Guarani, por exemplo. A consequência das alterações das fitofisionomias e dos processos erosivos é a diminuição da disponibilidade de água, explicando os resultados obtidos, em relação as áreas úmidas e de água superficial (Tabela 2), que foram reduzidas em 16,4\% e $20 \%$, respectivamente, possivelmente indicando os efeitos das ações antrópicas.

O processo de diminuição do volume de água pode estar relacionado a vários fatores (além das estações do ano), tais como o acesso de animais aos córregos, riachos e rios, onde o pisoteio do gado e abertura de trilhas proporciona maior escorrimento superficial, levando a processos de erosão e assoreamento. Também pode ocorrer a retirada parcial ou total da vegetação que protege os mananciais, tornando-os mais expostos a deposição de sedimentos; além deste fator, locais úmidos podem ser drenados 
para o plantio de grãos ou implantação de pastagens. Desta maneira, a retirada de grandes áreas de vegetação e outros processos antrópicos afetam os processos hídricos.

Oliveira et al. (2017a), em estudo sobre a Área de Proteção Ambiental dos Mananciais do Córrego Guariroba, Campo Grande, MS, também demonstraram que a retirada da vegetação nativa, permitindo maior escoamento superficial e aumento do processo de sedimentação na barragem, afetou negativamente a capacidade de armazenamento do reservatório, com redução de seu volume. Liu (2015) confirma a importância do uso de imagens de satélite para monitorar a qualidade ambiental, pois a coleta de dados (quantitativos e qualitativos) pode indicar o grau de degradação do ambiente e seu efeito sobre os recursos hídricos.

De acordo com Malheiros et al. (2012), em estudo em uma represa da região do Rio São Lourenço, Mato Grosso, a implementação das atividades agrícolas resultaram em modificações gradativas na qualidade da água e assoreamento da represa. Além disso, Calheiros, Dores e Oliveira (2006) escrevem que a contaminação de rios do Planalto, como o São Lourenço - MS/MT, por meio de atividades agropecuárias, possui ampla magnitude, com potencial para atingir a região do Pantanal Mato-Grossense. Possavatz et al. (2014) descrevem o mesmo problema, relatando a contaminação do Pantanal por pesticidas usados na bacia do Rio Cuiabá e seus tributários.

Em relação aos valores de NDVI, em 1990 a região possuía a maior parte dos resultados entre -0,1 e 0,4. Em 2005, entre -0,1 e 0,2. Já em 2020, entre 0,4 e 0,9 (Tabela 3). Estes dados podem indicar que ocorreu acúmulo de biomassa (aumento da complexidade da vegetação), pois quando os valores são mais próximos a 1, maior seria a tendência de uma cobertura vegetal mais abundante (embora o NDVI sofra a influência da assinatura espectral das imagens). Desta forma, quadros obtidos após algumas semanas poderiam indicar um NDVI diferente devido à nova assinatura espectral, embora o significado possa ser similar (formações vegetacionais mais complexas). $\mathrm{O}$ aumento dos valores de NDVI é uma informação importante, pois um maior valor indica que o solo possui maior cobertura vegetacional, seja nativa ou exótica e consequentemente, estará mais protegido da ação erosiva das chuvas. 
Tabela 3 - Índice de vegetação por diferença normalizada (NDVI) na área das nascentes do Rio Aquidauana, São Gabriel do Oeste, Mato Grosso do Sul, em 1990, 2005 e 2020

\begin{tabular}{|c|c|c|c|c|c|c|}
\hline \multirow{3}{*}{ Classes } & \multicolumn{2}{|c|}{1990} & \multicolumn{2}{|c|}{2005} & \multicolumn{2}{|c|}{2020} \\
\hline & \multicolumn{2}{|c|}{ Área } & \multicolumn{2}{|c|}{ Área } & \multicolumn{2}{|c|}{ Área } \\
\hline & $\mathrm{Km}^{2}$ & $\%$ & $\mathrm{Km}^{2}$ & $\%$ & $\mathrm{Km}^{2}$ & $\%$ \\
\hline$-0,9$ a $-1,0$ & 0,00 & 0,00 & 0,00 & 0,00 & 0,00 & 0,00 \\
\hline$-0,8$ a $-0,9$ & 0,00 & 0,00 & 0,00 & 0,00 & 0,00 & 0,00 \\
\hline$-0,7$ a $-0,8$ & 0,00 & 0,00 & 0,02 & 0,01 & 0,00 & 0,00 \\
\hline$-0,6$ a $-0,7$ & 0,01 & 0,01 & 0,04 & 0,01 & 0,00 & 0,00 \\
\hline$-0,5$ a $-0,6$ & 0,03 & 0,01 & 0,04 & 0,01 & 0,00 & 0,00 \\
\hline$-0,4$ a $-0,5$ & 0,32 & 0,07 & 0,05 & 0,01 & 0,00 & 0,00 \\
\hline$-0,3$ a $-0,4$ & 1,46 & 0,34 & 0,35 & 0,08 & 0,01 & 0,01 \\
\hline$-0,2$ a $-0,3$ & 12,58 & 2,89 & 24,30 & 5,59 & 0,03 & 0,01 \\
\hline$-0,1$ a $-0,2$ & 66,25 & 15,24 & 91,41 & 21,03 & 0,03 & 0,01 \\
\hline $0,0 a-0,1$ & 64,59 & 14,83 & 93,77 & 21,55 & 0,03 & 0,01 \\
\hline 0,0 a 0,1 & 74,25 & 17,08 & 98,53 & 22,67 & 1,39 & 0,32 \\
\hline 0,1 a 0,2 & 86,55 & 19,91 & 76,60 & 17,62 & 27,02 & 6,22 \\
\hline 0,2 a 0,3 & 73,04 & 16,80 & 32,81 & 7,55 & 6,91 & 1,59 \\
\hline 0,3 a 0,4 & 50,35 & 11,58 & 16,67 & 3,83 & 6,58 & 1,51 \\
\hline 0,4 a 0,5 & 5,15 & 1,18 & 0,08 & 0,02 & 32,43 & 7,46 \\
\hline 0,5 a 0,6 & 0,02 & 0,01 & 0,01 & 0,01 & 79,53 & 18,30 \\
\hline 0,6 a 0,7 & 0,03 & 0,01 & 0,01 & 0,01 & 87,89 & 20,22 \\
\hline 0,7 a 0,8 & 0,03 & 0,01 & 0,00 & 0,00 & 155,96 & 35,88 \\
\hline 0,8 a 0,9 & 0,02 & 0,01 & 0,00 & 0,00 & 36,80 & 8,47 \\
\hline 0,9 a 1,0 & 0,01 & 0,01 & 0,00 & 0,00 & 0,00 & 0,00 \\
\hline Total & 434,69 & 100,00 & 434,69 & 100,00 & 436,19 & 100,34 \\
\hline
\end{tabular}

Fonte: os autores.

Os resultados do NDVI para as áreas florestais podem indicar que em relação à complexidade do hábitat (estrutura vertical e fitomassa), as áreas florestais estão em processo de recuperação (Tabela 3, Figura 4). Levando-se em consideração onde ocorrem os maiores fragmentos florestais (Figura 2) e comparando-se com os índices obtidos de NDVI (Figura 4), observa-se que em 1990, as áreas florestais apresentavam coloração mais escura, com índices variando entre -0,5 e -0,2. Em 2005, entre -0,4 e 0,0. Em 2020, a maior parte com valores entre 0,2 e 0,5. Quanto mais próximo a 1, maior será a cobertura vegetal densa e um NDVI maior que 0,3 possui refletância maior no infravermelho, correspondendo a vegetação sadia (PONZONI; SHIMABUKURO; KUPLICH, 2012).

Este é um resultado importante, pois indica que os fragmentos restantes estão mais protegidos, permitindo sua recuperação. Porém, os dados apresentados por Gamarra et al. 
(2016), em estudos no Parque Estadual das Nascentes do Rio Taquari - MS, bioma Cerrado, com NDVI entre 0,745 e 0,963, demonstram que as áreas da Serra de Maracaju ainda estão fragilizadas, necessitando de mais tempo para se recuperar e atingir valores similares aos encontrados no Parque Estadual.

Os menores valores, registrados em 1990, indicariam um dossel menos denso, menor número de árvores por unidade de área e pouca biomassa. Essa situação pode ser resultado de retirada seletiva de madeira em períodos anteriores, utilizada para a construção de estruturas rurais, como cercas, casas ou galpões, por exemplo. Ou queimadas, devastando e empobrecendo a vegetação. Entretanto, de acordo com Ponzoni e Rezende (2004), nem sempre um maior NDVI significa vegetação mais conservada, pois clareiras vegetadas (zonas anteriormente desmatadas), por exemplo, apresentam altos valores de NDVI. Este resultado é relacionado a recuperação parcial da vegetação, com alta atividade fotossintética e refletividade, maior que nas zonas florestadas que dispersam mais a radiação devido a arquitetura e "porosidade óptica" do dossel.

Por outro lado, ocorreu uma modificação na dinâmica das áreas de pastagens. Em 1990, o NDVI variava entre -0,4 e 0,3, em 2005, entre -0,1 e 0,3 e, em 2020, entre 0,0 e 0,4 , demonstrando uma melhoria, com maior quantidade de biomassa. Estes locais estão localizados abaixo do platô da Serra de Maracaju, em solos arenosos de pouca fertilidade. Os menores valores encontrados inicialmente para algumas áreas indicariam o uso inadequado do solo, fator relacionado, por exemplo, ao excesso de animais nos locais, ocasionando pastoreio excessivo e levando a diminuição do volume da vegetação e variações mais próximas de -1, como em 1990 e 2005. É conhecido que pastagens degradadas são um sério problema ambiental, pois facilitam o escoamento superficial das águas, levando a processos erosivos e ao assoreamento dos recursos hídricos superficiais, o que já causa grandes prejuízos na bacia do Rio Taquari, que drena para os Pantanais de Paiaguás e Nhecolândia. Nestas regiões, os regimes de sedimentação foram acelerados pelo aumento de áreas degradadas no Planalto, levando a deposição de partículas nos rios, mudanças em seu curso e inundações em áreas que anteriormente não eram alagadas, com prejuízos econômicos e ambientais para toda a região, sendo os principais prejudicados a população residente, tais como os ribeirinhos (pescadores) e pequenos fazendeiros, além da fauna e flora nativa. 


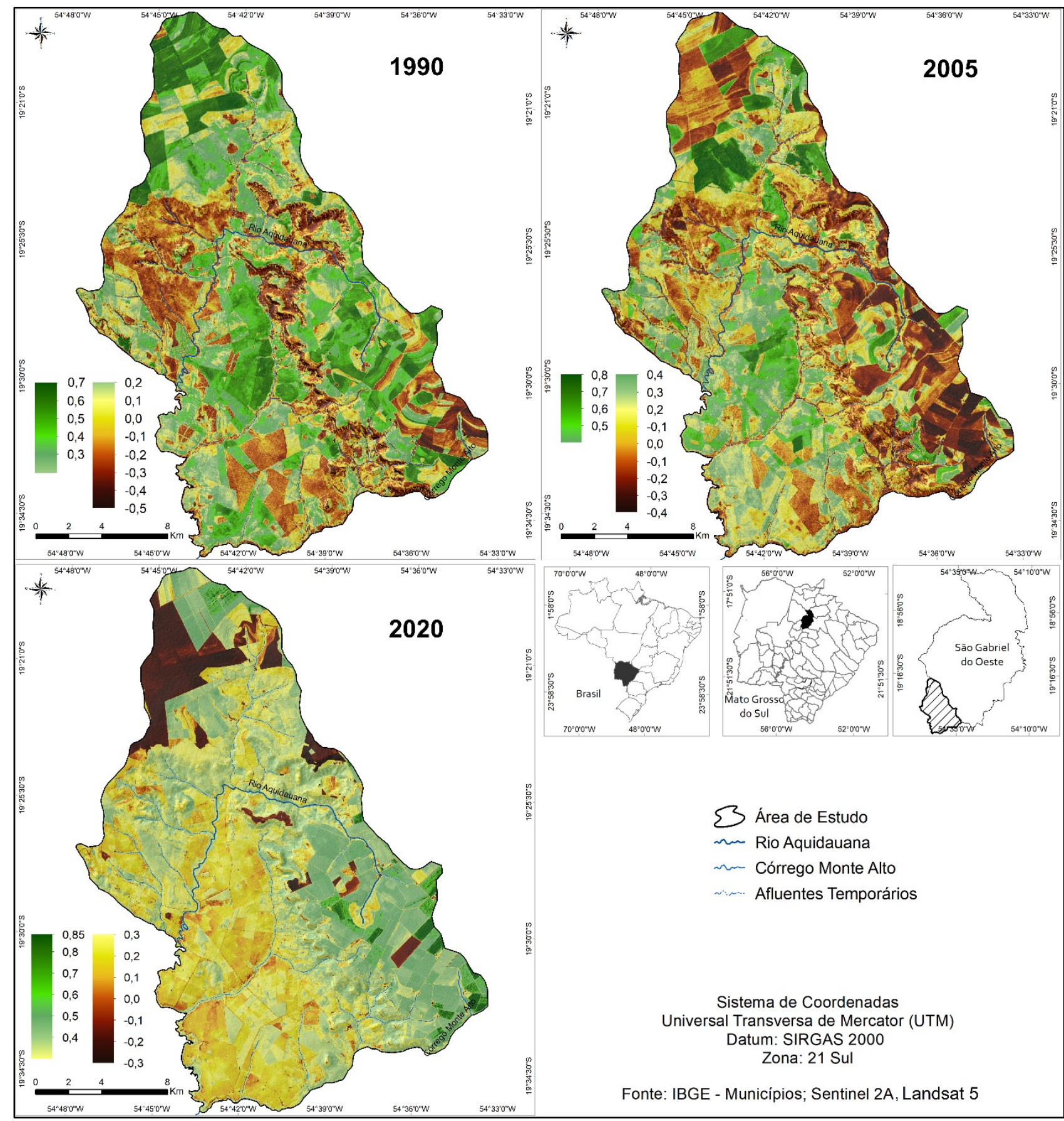

Figura 4 - Índice de vegetação por diferença normalizada (NDVI) na área das nascentes do Rio Aquidauana, São Gabriel do Oeste, Mato Grosso do Sul, em 1990, 2005, 2020 (Sistemas de coordenadas Universal Transversa de Mercator - Datum: SIRGAS 2000 - Zona 22 Sul).

Fonte: os autores.

Já os melhores índices em 2020 podem estar relacionados a alterações ocorridas nas áreas, resultado de processos de recuperação, renovação e/ou reforma dos locais, por exemplo, propiciando um melhor desenvolvimento das gramíneas. Por outro lado, também pode significar a supressão de áreas florestais, permitindo nos anos iniciais, um melhor crescimento da braquiária, devido a melhor qualidade nutricional do solo. Observando-se a situação sob outro prisma, o resultado desta melhora no NDVI também significa que os 
solos possuem maior cobertura vegetacional, evitando o escoamento superficial e processos erosivos. Os resultados encontrados corroboram as afirmações de Melo, Sales e Oliveira (2011) e Ponzoni, Shimabukuro e Kuplich (2012), onde o NDVI próximo a zero, caracterizado por refletância similar no visível e infravermelho, indica solo exposto ou pouco vegetado, enquanto valores mais elevados, solos mais bem vegetados, como em 2020.

Lima et al. (2020), avaliando as paisagens da Serra de Maracaju, também constataram que as dinâmicas territoriais historicamente construídas para a produção de commodities são as responsáveis pelas transformações das paisagens da região, por meio do desmatamento e avanço da agropecuária. Nesta situação, em áreas de relevo com pouca declividade e aptas para as atividades agropecuárias ocorre menor nível de preservação e conservação da vegetação, enquanto nas estruturas das paisagens que apresentam as maiores declividades existem os maiores índices de preservação, situação similar a observada neste trabalho.

\section{CONSIDERAÇÕES FINAIS}

A interpretação das imagens de satélite indicou um avanço das atividades agrícolas na porção norte, leste e sudeste na região das nascentes do Rio Aquidauana, sobretudo sobre as áreas florestadas existentes em 1990. Ocorreu o decréscimo de florestas nativas de 1990 para 2020, em 5,14\%, com maior concentração no período de 2005 a 2020, com $3,08 \%$. Apesar do avanço das atividades antrópicas, as formações vegetais nativas ainda existentes aumentaram sua complexidade estrutural (biomassa) nos anos estudados, o que demonstra que a vegetação ficou mais densa, fato constatado nos índices de NDVI de 2020. No mesmo período, verificou-se o aumento da área agricultável em $10,64 \%$, o que pode ser uma ameaça aos corpos de águas superficiais e as zonas de recarga dos Aquíferos Bauru/Guarani e contribuir para o assoreamento do Rio Aquidauana e da planície pantaneira. O relevante ressaltar que o índice NDVI permaneceu com pequenas variações em determinadas regiões antropizadas, demonstrando que a agricultura comercial, sempre verde, mesmo com pequeno porte vegetal, produz biomassa suficiente para produzir uma assinatura espectral relativamente semelhante ao Cerrado.

Os resultados obtidos indicam a necessidade do planejamento racional no uso e ocupação do espaço, pois a utilização da natureza de forma desenfreada, apenas sob o enfoque econômico e utilitarista, sem nenhuma preocupação com a escassez hídrica, é um risco para não só o ambiente natural, mas também para as atividades econômicas exercidas pelo homem. A visão mercantilista do ambiente levou a redução das áreas 
florestais e como consequência, a perda dos mananciais hídricos. Algumas regiões do Pantanal já sofrem com os processos de sedimentação que foram acelerados por processos erosivos ocorridos no Planalto, levando a mudanças no curso de rios e inundações em áreas que anteriormente não eram alagadas, com prejuízos a fauna, flora e as populações residentes, como pescadores e fazendeiros. Deste modo, dever-se-ia considerar, no processo de ocupação das áreas, as consequências a curto, médio e longo prazo de tais atos, pois sem um planejamento ambiental adequado, os resultados sempre serão negativos, para o homem e o ambiente.

\section{AGRADECIMENTOS}

Os autores agradecem à Universidade Anhanguera-Uniderp pelo financiamento do projeto e ao Conselho Nacional de Desenvolvimento Científico e Tecnológico (CNPq) e a Coordenação de Aperfeiçoamento de Pessoal de Nível Superior (CAPES), pelas bolsas de produtividade (PQ1 e PQ2) e de estudos, respectivamente concedidas.

\section{REFERÊNCIAS}

ASSIS, D. S.; COSTA, J. R. S.; TÔSTO, S. G.; GOMES, J. B. V.; MACEDO, J. R.; MARTINS, J. S.; MARQUES, J.; ALVARENGA, S. M.; MOREIRA, M. L. O.; RAMALHO FILHO, A.; et al. Zoneamento agroecológico do município de São Gabriel do Oeste, MS: Referencial para o planejamento, gestão e monitoramento territorial. Rio de Janeiro: Embrapa Solos, 2003. 177p.

BONONI, V. L. R.; OLIVEIRA, A. K. M.; GUGLIOTTA, A. M.; QUEVEDO, J. R. Agaricomycetes (Basidiomycota, Fungi) diversity in a protected area in the Maracaju Mountains, in the Brazilian central region. Hoehnea, São Paulo, v. 44, n. 3, p. 361-377, 2017. http://dx.doi.org/10.1590/2236-8906-70/2016

BARBOSA, C. C. F.; NOVO, E. M. L. M.; MARTINS, V. S. Introdução ao sensoriamento remoto de sistemas aquáticos: princípios e aplicações. São José dos Campos: Instituto Nacional de Pesquisas Espaciais, 2019. 161p

BRASIL. Folha SE. 21 Campo Grande: geologia, geomorfologia, pedologia, vegetação e uso potencial da terra. Levantamento de Recursos Naturais. v. 28. Projeto RADAM-BRASIL. Rio de Janeiro: Ministério das Minas e Energia. Departamento Nacional da Produção Mineral, 1982. 416p.

BRIASSOULIS, $\mathrm{H}$. Analysis of land use change: theoretical and modeling approaches. Web Book of Regional Science. 3. Virginia: Regional Research Institute, West Virginia University, 2019. 243p. 
CALHEIROS, D. F.; DORES, E. F. G.; OLIVEIRA, M. D. Poluição por pesticidas, nutrientes e material em suspensão nos rios formadores do Pantanal Matogrossense. Corumbá: Embrapa Pantanal, 2006. 4p.

CÂNDIDO, A. K. A. A.; SILVA, N. M.; BARBOSA, D. S. Dinâmica espacial e temporal do uso do solo e Índice de Vegetação por Diferença Normalizada (NDVI) em setor de Cabeceira do Rio São Lourenço, Campo Verde, MT. Revista RA'EGA - O Espaço Geográfico em Análise, Curitiba, v. 33, p. 94-119, 2015. http://dx.doi.org/10.5380/raega.v33i0.36338

CARVALHO, F. M. V.; MARCO JÚNIOR, P.; FERREIRA, L. G. The Cerrado into-pieces: Habitat fragmentation as a function of landscape use in the savannas of central Brazil. Biological Conservation, Essex, v. 142, n. 7, p. 1392-1403, 2009. http://dx.doi.org/10.1016/j.biocon.2009.01.031

DAMASCENO-JUNIOR, G. A.; POTT, A.; NEVES, D. R. M.; SCIAMARELLI, A.; FINA, B. G. Flora lenhosa de Florestas estacionais do estado de Mato Grosso do Sul: estado da arte. Iheringia, Série Botânica, Porto Alegre, v. 73, p. 65-79, 2018. https://doi.org/10.21826/2446-8231201873s65

FORMAGGIO, A. R.; SANCHES, I. D’A. Sensoriamento remoto em agricultura. São Paulo: Editora Oficina de Textos, 2017. 288p.

GAMARRA, R. M.; TEIXEIRA-GAMARRA, M. C.; CARRIJO, M. G. G.; PARANHOS FILHO, A. C. Uso do NDVI na análise da estrutura da vegetação e efetividade da proteção de Unidade de Conservação no Cerrado. Revista RA'EGA - O Espaço Geográfico em Análise, Curitiba, v. 37, p. 307-332, 2016. http://dx.doi.org/10.5380/raega.v37i0.42454

GUEDES, J.; SILVA, S. M. P. Sensoriamento remoto no estudo da vegetação: princípios físicos, sensores e métodos. Acta Geográfica, Boa Vista, v. 12, n. 29, p. 127-144, 2018. http://dx.doi.org/10.5654/acta.v12i29.4001

GUERRA, A. J. T.; JORGE, M. C. O. Degradação dos solos no Brasil. Rio de Janeiro: Bertrand Brasil, 2014. 320p.

HARRIS, M. B.; ARCÂNJO, C.; PINTO, E. C. T.; CAMARGO, G.; NETO, M. B. R.; SILVA, S. M. Estimativa da perda de cobertura vegetal original na Bacia do Alto Paraguai e Pantanal brasileiro: ameaças e perspectivas. Revista Natureza \& Conservação, Curitiba, v. 4, n. 2, p. 50-66, 2006.

IBGE. Instituto Brasileiro de Geografia e Estatística. Manual Técnico da Vegetação Brasileira. 2.ed. Rio de Janeiro: IBGE, 2012. 275p

JOIA, P. R.; ANUNCIAÇÃO, V. S.; PAIXÃO, A. A. Implicações do uso e ocupação do solo para o planejamento e gestão ambiental da Bacia Hidrográfica do Rio Aquidauana, Mato Grosso do Sul. Interações, Campo Grande, v. 19, n. 2, p. 343-358, 2018. https://doi.org/10.20435/inter.v19i2.1404

LIMA, B. S.; SILVA, C. A.; BOIN, M. N.; MEDEIROS, R. B. As paisagens e as dinâmicas territoriais na Serra de Maracaju, Mato Grosso do Sul, Brasil. Cuadernos de Geografía: 
Revista Colombiana de Geografía, Bogotá, v. 29, n. 1, p. 224-241, 2020. https://doi.org/10.15446/rcdg.v29.n1.75016

LIU, W. T. H. Aplicações de sensoriamento remoto. 2.ed. São Paulo: Oficina de Textos, 2015. 908p.

MALHEIROS, C. H.; HARDOIM, E. L.; LIMA, Z. M.; AMORIM, R. S. S. Qualidade da água de uma represa localizada em área agrícola (Campo Verde, MT, Brasil). Ambiente \& Água, Taubaté, v. 7, n. 2, p. 245-262, 2012. https://doi.org/10.4136/ambi-agua.904

MARANHAO, R. L. A.; VIEIRA FILHO, M. J. E. R. A dinâmica do crescimento das exportações do agronegócio brasileiro. Brasília: Rio de Janeiro: Ipea, 2016. 50p.

MARTINELLI, M. Cartografia ambiental, uma cartografia diferente? Revista do Departamento de Geografia, São Paulo, v. 7, p. 61-80, 1994. https://doi.org/10.7154/RDG.1994.0007.0005

MATO GROSSO DO SUL. Zoneamento Ecológico-Econômico do Estado de Mato Grosso do Sul - Segunda aproximação. Elementos para construção da sustentabilidade do território sul-matogrossene. Campo Grande: ZEE-MS, 2015. 199p.

MELO, E. T.; SALES, M. C. L.; OLIVEIRA, J. G. Aplicação do Índice de Vegetação por Diferença Normalizada (NDVI) para análise da degradação ambiental da Microbacia Hidrográfica do riacho dos Cavalos, Crateús-Ce. Revista RA'EGA - O Espaço Geográfico em Análise, Curitiba, v. 23, p. 520-533, 2011. http://dx.doi.org/10.5380/raega.v23i0.24919

MIRANDA, M. P.; DUARTE, C. R.; GOMES, D. D. M.; SOUZA, C. D.; SILVA NETO, C. Â. Análise comparativa de imagens Sentinel-2A (MSI) e Landsat-8 (OLI) aplicadas ao mapeamento geológico, Região de Itataia, Santa Quitéria, CE. Anuário do Instituto de Geociências, Rio de Janeiro, v. 40, n. 3, p. 254-265, 2019. http://dx.doi.org/10.11137/2019_2_366_377

OLIVEIRA, A. K. M.; FERNANDES, V.; GARNÉS, S. J. A.; SANTOS, C. R. B. Avaliação da perda da vegetação arbórea nativa na Serra da Bodoquena, Mato Grosso do Sul, por meio de sensoriamento remoto. Revista RA'EGA - O Espaço Geográfico em Análise, Curitiba, n. 17, p. 43-52, 2009. http://dx.doi.org/10.5380/raega.v17i0.12657

OLIVEIRA, A. K. M.; OLIVEIRA, M. D.; FAVERO, S.; OLIVEIRA, L. F. Diversity, similarity and trophic guild of chiropterofauna in three southern Pantanal sub-regions, State of Mato Grosso do Sul, Brazil. Acta Scientiarum. Biological Sciences, Maringá, v. 34, n. 1, p. 3339, 2011. http://dx.doi.org/10.4025/actascibiolsci.v34i1.7596

OLIVEIRA, A. K. M.; FERNANDES, V.; PIRAJÁ, R. V.; SILVA, M. H. S. Avaliação multitemporal das paisagens da Área de Proteção Ambiental (APA) dos Mananciais do Córrego Guariroba, Campo Grande, Mato Grosso do Sul, por meio de imagens de satélites. Revista RA'EGA - O Espaço Geográfico em Análise, Curitiba, v. 42, p. 8-20, 2017 a. http://dx.doi.org/10.5380/raega.v42i0.43753

OLIVEIRA, A. P. G.; MIOTO, C. L.; DALMAS, F. B.; ALBREZ, E. A.; MELOTTO, A.; FACINCANI, E. M.; GAMARRA, R. M.; PARANHOS FILHO, A. C. Análise multitemporal da 
cobertura vegetal de São Gabriel do Oeste, MS. Anuário do Instituto de Geociências, Rio de Janeiro, v. 40, n. 3, p. 254-265, 2017b. http://dx.doi.org/10.11137/2017_3_254_265

PARANHOS FILHO, A. C.; GAMARRA, R. M. SIG - Sistema de informações geográficas. In: PARANHOS FILHO, A. C. et al. (Orgs.). Geotecnologias para aplicações ambientais. Maringá: Uniedesul, 2021. p. 163-181.

PETTORELLI, N. The Normalized Difference Vegetation Index. Oxford: Oxford University Press, 2014. 224p.

PIGNATI, W. A.; LIMA, F. A. N. S.; LARA, S. S.; CORREA, M. L. M.; BARBOSA, J. R.; LEÃO, L. H. C.; PIGNATTI, M. G. Distribuição espacial do uso de agrotóxicos no Brasil: Uma ferramenta para a Vigilância em Saúde. Ciência \& Saúde Coletiva, Rio de Janeiro, v. 22 , n. 10 , p. 3281-3293, 2017. https://doi.org/10.1590/1413-812320172210.17742017

PONZONI, F. J.; REZENDE, C. P. Caracterização espectral de estágios sucessionais de vegetação secundária arbórea em Altamira (PA), através de dados orbitais. Revista Árvore, Viçosa, v. 28, n. 4, p. 535-545, 2004. https://doi.org/10.1590/S010067622004000400007

PONZONI, F. J.; SHIMABUKURO, Y. E.; KUPLICH, T. M. Sensoriamento remoto da vegetação. 2.ed. São Paulo: Oficina de Textos, 2012. 176p.

POSSAVATZ, J.; ZeILhOFER, P.; PINTO, A. A.; TIVES, A. L.; DORES, E. F. G. C. Resíduos de pesticidas em sedimento de fundo de rio na Bacia Hidrográfica do Rio Cuiabá, Mato Grosso, Brasil. Revista Ambiente e Água, Taubaté, v. 9, n. 1, p. 83-96, 2014. https://doi.org/10.4136/ambi-agua. 1263

REGO, N. H.; VALERI, S. V. Variação da estrutura da vegetação arbórea em uma topossequência num vale da Serra de Maracaju, Aquidauana, MS. 2008. Tese (Doutorado em Agronomia). Faculdade de Ciências Agrárias e Veterinárias, Universidade Estadual Paulista Júlio de Mesquita Filho, Jabuticabal.

RIVERO, S.; ALMEIDA, O.; ÁVILA, S.; OLIVEIRA, W. Pecuária e desmatamento: uma análise das principais causas diretas do desmatamento na Amazônia. Nova Economia, Belo Horizonte, v. 1, n. 19, p. 41-66, 2009. https://doi.org/10.1590/S010363512009000100003

ZANOTTA, D. C.; FERREIRA, M. P.; ZORTEA, M. Processamento de imagens de satélite. São Paulo: Editora Oficina de Textos, 2019. 320p.

ZAVATTINI, J. A. As chuvas e as massas de ar no Estado de Mato Grosso do Sul: estudo geográfico com vista à regionalização climática. São Paulo: Editora UNESP/Cultura Acadêmica, 2009. 212p. (Coleção PROPG Digital - UNESP). 